\title{
From vulnerable to responsible youth? Indonesian youth resisting the dominant discourse of sexual health
}

\section{Teguh Wijaya Mulya}

To cite this article: Teguh Wijaya Mulya (2019): From vulnerable to responsible youth? Indonesian youth resisting the dominant discourse of sexual health, Psychology \& Sexuality, DOI: 10.1080/19419899.2019.1604566

To link to this article: https://doi.org/10.1080/19419899.2019.1604566

曲 Published online: 13 Apr 2019.

Submit your article to this journal $\widetilde{ }$

View Crossmark data $₫$ 


\title{
From vulnerable to responsible youth? Indonesian youth resisting the dominant discourse of sexual health
}

\author{
Teguh Wijaya Mulya (D) \\ Faculty of Psychology, University of Surabaya, Surabaya, Indonesia
}

\begin{abstract}
Contemporary critical studies have identified that the dominant discourse of sexual health has positioned youth as hormone-driven, vulnerable, uninformed, and in need to be 'saved' by sexuality educators. The current article aims to explore possibilities to destabilise such positioning by examining alternative sexual subjectivities among youth in an Indonesian context. As many as 22 participants were interviewed through the Internet (e.g. email and instant messenger interviews) and the data were analysed using a discourse analysis method. Their narratives demonstrate that youth are not simply hormone-driven, uninformed, and vulnerable. Instead, they are agentic subjects who - within their limited discursive access - actively, creatively, and subversively learn about sexuality in order to take care of their well-being. The implications are discussed in relation to how sexual health education may accommodate the complexity of youth's sexual subjectivities.
\end{abstract}

ARTICLE HISTORY

Received 23 October 2018

Accepted 29 March 2019

\section{KEYWORDS}

Sexual health; sexual subjectivity; discourse; youth; Indonesia

The discourse of sexual health has been widely drawn upon by previous researchers in understanding youth sexuality (e.g. Flanders, Ross, Dobinson, \& Logie, 2017; Teye-Kwadjo, Kagee, \& Swart, 2017), including in Indonesian contexts (e.g. Diarsvitri, Utomo, Neeman, \& Oktavian, 2011; Leerlooijer et al., 2011; Widyastari, Isarabhakdi, \& Shaluhiyah, 2015). The discourse of sexual health is a formation of taken-for-granted ideas that position health as the principal axis in giving meaning to sexuality. This discourse offers ways to think about, practise, and evaluate sexual experiences in terms of health criteria, such as mental, emotional, and social well-being and, most notably, the absence of sexually transmitted infections (STIs) and unplanned pregnancy. The current article aims to (1) argue that this discourse has been dominant in the existing literature on youth sexuality in Indonesia, and foreground its problematic consequences; and (2) explore alternative sexual subjectivities among Indonesian youth which may contest this dominant discourse. Sexual subjectivity here refers to an individual's thoughts and emotions about their sense of being sexual, which are constituted in relation to particular discourses available in their situation (Weedon, 1987).

The article begins with a critical review of studies on sexual health among Indonesian youth, focusing on how the discourse of sexual health has positioned Indonesian youth as uninformed, vulnerable, and in need to be 'saved' by sexuality educators. After the methodology of the study is described, the article empirically demonstrates how such positioning has been resisted by young Indonesian participants in their becoming of a sexual subject. In this article, the diversity of sexual identities (gay, lesbian, bisexual, heterosexual, etc.) is respected and taken for granted. 


\section{From vulnerable to responsible youth: the problem with the discourse of sexual health}

In this Muslim-majority country where traditional norms around youth sexuality - such as abstinence, heteronormativity, and modesty - are publicly encouraged, concerns about youth's sexual behaviours, STIs, and unplanned pregnancy have grown significantly especially since the 1990s. This growing interest is often attributed to the arrival of HIV/AIDS (Smith, Kippax, \& Aggleton, 2000), more relaxed cultural values around dating relationships (Smith-Hefner, 2005), and increased access to the so-called 'Western' discourse of sexual permissiveness (Harding, 2008; Utomo \& McDonald, 2009). Many studies emphasised health risks associated with Indonesian youth's sexual behaviours, such as STIs and unplanned pregnancy (e.g. Munro \& Butt, 2012; Simon \& Paxton, 2004). These researchers call for sexuality education programmes which address these risks, specifically those promoting consistent condom-use (e.g. Diarsvitri et al., 2011; Leerlooijer et al., 2011; Widyastari et al., 2015). In response to this call, the Ministry of Health and a number of NGOs (non-governmental organisations) have sporadically conducted sexuality education programmes for Indonesian youth; the effectiveness of these programmes has also been the focus of a number of studies. These studies evaluated sexuality education mainly using sexual health criteria such as reproductive health knowledge and avoidance of unprotected sexual behaviours (Diarsvitri \& Dwisetyani, 2011; Leerlooijer et al., 2011; Pohan et al., 2011). The extensive use of such criteria among these studies indicates that the (re)production of academic knowledge around Indonesian youth and sexuality has been informed by the discourse of sexual health.

Uncritical reliance on this discourse in researching and understanding youth sexuality has resulted in at least two problematic consequences. Firstly, it positions Indonesian youth as uninformed and vulnerable in relation to sexuality. In addressing Indonesian youth, sexual health researchers often position them as (potential) health patients who have no knowledge about their own (sexual) body, are blinded by raging hormones, and therefore urgently need to be 'saved' by sexual health educators before they are inevitably driven into unprotected sex (e.g. Diarsvitri et al., 2011; Leerlooijer et al., 2011; Widyastari et al., 2015). Fields (2008, p. 20) calls this situation 'adultist protectionism,' in which youth are constituted as sexually innocent, ignorant, hormone-driven, and their engagement in sexual activity is perceived as a social problem for adults to solve.

This positioning, however, is problematic when such a dominant constitution of youth is constantly repeated, to the extent that other ways of giving meaning to Indonesian youth's sexual subjectivities become unthinkable. Youth as actively engaging with, and critical of, sexual information they received from various sources, for instance, were not recognised. Continuous positioning of youth as ignorant, hormone-driven, and in need of protection has constrained the constitution of youth as capable of making responsible and informed sexual decisions (Allen, 2007), which, ironically, has often been identified as the goal of contemporary sexual health promotion in Indonesia (Bennett, 2007; Diarsvitri \& Dwisetyani, 2011; Widyastari et al., 2015). To the best of the author's knowledge, there is no study specifically documenting the ways in which this dominant positioning might be/have been contested in Indonesian contexts. This is a gap that this article aims to fill, that is, by exploring how youth participants in this study have resisted this positioning that lies at the centre of the discourse of sexual health.

The second problem with the dominant discourse of sexual health is that it has promoted a mechanistic logic: if youth are provided with sexual health knowledge, they will follow the suggested risk management procedures and thus effectively avoid STIs and unplanned pregnancy (e.g. Pohan et al., 2011; Widyastari et al., 2015). Through this discourse youth are positioned as vulnerable and uninformed before the provision of sexual health information; after this provision they are constituted as 'enlightened' and responsible sexual subjects. The provision of sexual health knowledge by adults becomes a critical turning point: from ignorance to enlightenment, from vulnerability to capability. 
International studies have demonstrated that this logic is flawed (Braun, 2013; Flood, 2003; Kippax, 2010). Consistent condom-use, for example, was not easily practised by youth in their sexual relationships although they had adequate knowledge about STIs and condoms (Braun, 2013; Flood, 2003). One explanation identified by these researchers is the construction of the condom as difficult to use, disrupting sex, and inhibiting intimacy. Knowledge about STIs and condoms given to youth does not therefore translate straightforwardly into practice. Another explanation is that youth might have their own conceptualisations of sexual knowledge which are gleaned from their personal experiences (Allen, 2001) in the form of practical wisdom to make judgements and decisions (Fletcher, 2015). In contrast, official sexual health programmes often focus on facts-based, technical, and presumed-objective knowledge. While these studies have highlighted that the mechanistic logic underpinning sexual health promotion is problematic, to date there is no study involving Indonesian youth that has taken these critiques into account. This is another gap this study seeks to fill, that is, by demonstrating the ways Indonesian youth contested this mechanistic logic in their becoming a sexual subject.

\section{Method}

\section{Methodological framework}

This study is (in)formed by a Foucauldian discourse analysis methodology (Willig, 2013). Discourse refers to a set of interconnected ideas through which individuals understand their experience (Weedon, 1987), including their sense of self (i.e. subjectivity). Subjectivity is not viewed as fixed, coherent, or static; but is constituted via active and continuous acts of constituting one's own experiences, which are enabled by discourses available in any given situation. Following this theorization of subjectivity, participants' narratives in this study are not understood as 'their stories,' but discursively (re)produced - contingently and collaboratively - within our researcher-participant relationship. To a degree, the researcher and the researched become co-researcher, co-participant, and co-shaper of data, both are enabled and constrained by discourses available to us in this research context. The interviews, for example, were not conducted in a structured way that would emphasise the researcher's authority, but to stimulate dialogue through open-ended questions.

Traditionally, such collaborative commitment is enacted through a procedure of participant validation of the final analysis. In this study, it was not conducted because of several considerations. Firstly, the academic language used in the final analysis might not be accessible to most participants (Josselson, 2007). Secondly, discussing work-in-progress does not necessarily lead to an agreement on how the interpretation should be made (Chase, 1996). Some differences might never be resolved, particularly when participants' views largely reflect dominant or oppressive power relations. Thirdly, participants' subjectivity are multiple and changing, while researchers' analyses of participants' subjectivity are contingent and selective (Josselson, 2007). Fourthly, a belief that participants can, and should, independently speak for themselves is 'illusory' (Borland, 1991, p. 64) and against post-structuralist view of subjectivity as discursively-constituted within specific power relations. Therefore, as suggested by Chase (1996) and Josselson (2007), the position I adopted in this research is that I openly and honestly claim interpretive authority. I acknowledge that the final analysis is my interpretation of participants' narratives, which has been written as respectfully as I can with regard to their dignity.

Further, the data in this study is not understood as a transparent window into participants' lives; instead, it is understood as discursively constituted within the interactions between the researcher, participants, and research contexts (e.g. interview settings, poststructuralist methodology). This approach to data, coupled with an understanding of subjectivity as unstable and continuously reworked, might raise some methodological concerns. As Browne and Nash (2010, p. 1) have questioned:

[If] subjects and subjectivities are fluid, unstable and perpetually becoming, how can we gather "data" from those tenuous and fleeting subjects using the standard methods of data collection such as interviews and questionnaires? What meanings can we draw from, and what use can we make of such data when it is only momentarily fixed and certain? 
Taking this concern into account, the methodology of this study does not search for fixed or stable ways that participants understand themselves as sexual subjects. Rather, it acknowledges the fluidity and instability of their subjectivity. Data are understood as a small mark in the multiple and endless paths of understanding participants' sexual subjectivity. With this approach to data, traditional criteria to evaluate qualitative data (e.g. confirmability, dependability, triangulation) might not be relevant. The significance of my data is not rooted in its fixity or stability, but in the opportunity it offers to identify ruptures and cracks of the regulatory regime (Butler, 1990). It is this possibility of discursive openings that I use to justify the quality of the multiple, tenuous, and fleeting accounts of participants' sexual subjectivities.

\section{Participants}

The participants were recruited as a part of my research on Indonesian youth's sexual subjectivities (Wijaya Mulya, 2017, 2018). After ethics permission was obtained from the university's ethics authority (ref. number 9046), the researcher distributed the advertisement to NGOs, universities, and communities in several cities in Indonesia (concealed for confidentiality) between April and May 2013. The advertisement explicitly stated 'unique and different perspectives are welcomed' and 'no judgment' to attract youth who are disruptive towards the dominant sexual norms. Following the ethics committee's standards, the minimum age was set on 16 so that parental consent was not legally required. The target size was 20-30 participants.

Representative sampling was not pursued in this study, as it is against aforementioned methodological framework. It is also important to note that Indonesia has an extraordinary diversity in terms of culture, tradition, religion, geographical location, and social norms. Therefore, dominant sexual discourses among Indonesian youth could also be different across communities; and consequently, the participants and findings of this study do not represent or apply to all Indonesian youth.

Twenty-four young Indonesians aged 16-24 made contact via email and/or the short message service, and were sent the Participant Information Sheet (PIS) and consent form. Ten participants wanted to see the researcher in person to ask questions before signing the consent form, while the others signed and returned the consent form electronically. All participants agreed to take part, except one. After reading the PIS, she decided she was unsuitable for this study because she felt she had no stories or experiences around sexuality. Another participant did not reply emails at all after initially agreeing. Three others decided to stop halfway through the data production because they were busy with their studies. However, they chose not to withdraw their participation entirely so their narratives are included in this study. The final number of participants was 22.

Twelve participants identified as male, nine as female, and one as neither gender. Fourteen identified as heterosexual, 4 gay, 2 lesbian, 1 bisexual, and 1 asexual. At the time of the interview, 8 participants were college students, 6 high school students, 5 employees, 1 freelance journalist, 1 postgraduate student, and 1 NGO activist. All participants were from urban Indonesian contexts, and none of them were married at the time of the recruitment. In terms of socio-economic status, the range was relatively wide, from a financially secure participant who studied overseas, to ex-street children who lived in a shelter. Their experiences of sexual activity were also diverse, including maintaining strict abstinence or regularly engaging in sex. All participant names in this article are pseudonyms.

\section{Data construction}

The data construction involved email interviews (10-20 correspondences per participants), an instant messenger interview (to probe more specific topics participants have brought up in the email interview), and an autobiographical writing (to give participants time and space to think, (re)construct, and articulate their experiences in their own way) between April and October 2013. The interviews were all conducted by the researcher in Bahasa Indonesia and translated into English also by the researcher 
himself for this article. A competent colleague rechecked the translation to ensure accuracy. The interview topics were about the way participants understand themselves as a sexual being, including but not limited to - their sexual identity, sexual learning, sexual experience, sexual health, and sexual ethics/morality. The researcher required participants to have regular access to the Internet at least once a week, which might have excluded some potential participants, such as those of lower socio-economic status. However, during recruitment none of the potential participants withdrew and none of community keypersons complained in relation to this requirement. This situation might indicate the limitation of my recruitment networks which relied on urban middle-class communities/institutions. The exceptions to this were the ex-street children participants living in a shelter which has Internet access. One of the challenges during the data construction was the limited modalities to build rapport (i.e. only via email correspondence). To tackle this, the researcher carefully and reflexively built rapport and trust in the early phase of data construction, such as by revealing his own struggle with sexual norms or emphasising his openness to unique and different stories.

\section{Data analysis}

After combining email correspondence, instant messenger chats, and autobiographical narratives into word-processor files, the researcher analysed the data inductively using thematic analysis techniques suggested by Braun and Clarke (2006). I first familiarised myself with data, generated initial themes, then searched, reviewed, and defined the underlying discourses. In accordance with the focus of this study, throughout the analysis I looked for themes around the ways participants resisted the dominant discourse of sexual health in the constitution of their sexual subjectivity. The analysis did not aim to be comprehensive nor representing general patterns of all participants' sexual subjectivity, but to identify possibilities to destabilise or disrupt the dominant discourse of sexual health in an Indonesian context.

\section{Findings and discussion}

The data analysis reveals that participants do not simply adopt dominant meanings or take up subject positions offered by the discourse of sexual health. Instead, the formation of their sexual subjectivities is complex and contradictory, involving both engagement with, and contestation of, the dominant discourse of sexual health. The current analysis focused on the latter, that is, how their narratives exhibit other, competing, versions of giving meaning to their sexual selves, which do not always draw on the notion of health risk avoidance in understanding their sexual practices. Young Indonesian participants do not always understand themselves as vulnerable and passively waiting for adults to 'save' them by providing sexual health information. Instead, they are agentic sexual subjects, who actively learn and take care of, their (sexual) selves via the mobilisation of the discourses available to them. Specifically, the following sections will demonstrate how some participants' narratives have contested the positioning of youth as (1) hormone-driven sexual subjects, and (2) uninformed and vulnerable.

\section{Resisting the positioning of youth as hormone-driven sexual subjects}

Participants' narratives showed that the positioning of youth as hormone-driven sexual subjects through the discourse of sexual health does not always correspond to their ways of being sexual. Some participants have drawn on other discourses which resisted this positioning in their talk about their sexual experiences.

Mawar (21, college student, female, heterosexual) is one of these participants. She has had a number of dating relationships since she was in intermediate school. At that time her father did not allow her to date. She describes her past relationships as 'some serious and some were just puppy love' (email interview). When she participated in this study she was not living with her parents 
but in a student boarding house close to her university in another town. She considers her sexual knowledge as 'very little' (email interview) because there was no sexuality education at all at her school and she has 'never watched or read about sexuality' (email interview). The only moment her parents talked about sexuality was a short message about the importance of virginity for girls. When Mawar's narrative is given meaning through the discourse of sexual health, her situation could be perceived as 'risky.' She is lacking sexual knowledge, lacking in parental supervision, and has had many dating experiences even before she was allowed to date. Coupled with the positioning of youth as hormone-driven sexual subjects, Mawar is at risk of engaging in sex without knowing the dangers awaiting her. However, Mawar resisted such positioning by drawing on discourses she had access to that do not constitute sex as something that youth are inevitably driven into in their dating relationships. She did not engage in sexual activities with her boyfriends and it was not difficult for her to stay away from sexual activities (other than kissing).

I have been dating since I was in intermediate school, but I've never done (sexual) things I'm not supposed to do. In my dating relationships, the furthest I did was just kissing. I've never gone further than that. My boyfriend(s) never asked more than that anyway. (Email interview.)

Similarly, Anggi's narrative (22, office worker, female, heterosexual) also evidences how some participants have resisted the positioning of youth as always wanting sex. Anggi grew up in a small town in Indonesia, and then studied overseas for her tertiary education where she met new friends from different countries. A dominant theme in Anggi's narrative is the topic of preserving virginity, which she understands as maintaining a condition in which one has never had sexual intercourse. Anggi often expresses her opposition toward the dominant norm of preserving virginity before marriage in Indonesian societies:

\footnotetext{
Most of my friends in my hometown still think like people in the past, they consider having sex before marriage is totally wrong, plus they got pregnancy scares. So they still consider having sex before marriage = big mistake, broken life, equated with drug addicts, or notorious clubbers. My new friends here are diverse, they come from various parts of the world, so their thinking is very different. Their value is 'work hard, play hard.' So they consider sex is okay, as long as you are responsible. If you wanna party just party but don't let it too loose, don't drink too much, don't get too drunk, don't stay nearby strangers that look suspicious, just stay away from trouble. And I think ITS LOGICAL! I mean come on, who doesn't need sex? At least know about it. We are grown-ups. We have to know what's going on. ... Losing your virginity isn't like losing both of your hands. (Email interview.)
}

Anggi once posted a status on her social media page about her attitude toward virginity. She was then immediately accused by a friend of no longer being a virgin and of having sex repeatedly. Anggi's frank and provocative language in undermining the importance of virginity has made her vulnerable to such accusations. However, openly opposing the preservation of virginity does not mean Anggi is inevitably driven to engage in sex. In fact, Anggi still maintained her virginity at the time I interviewed her. When I asked why, she gave two reasons:

1. Painful. LOL. I heard that the first time is painful, so I better don't do it now, and I don't know if my partner will be good or not. What if he just pretends he's good then it hurts? A friend told me that she had sex with a guy who was not really serious with her, and the guy just 'stabbed' her like that, and she cried painfully. So I am a bit afraid. (sorry for my frank language. LOL). And the second reason, I haven't found a boyfriend who makes me feel 'I'm into him,' so that I wanted to have sex with him. This is my own boundary. If I'm not really in love and not really serious, I won't have sex with him, rather than regret it. (Email interview.)

At the time of the interview Anggi lived far away from her parents, had a boyfriend who was sexually experienced, did not think virginity was essentially important, had close friends who engaged in sexual activities, and is knowledgeable about safer sex, STIs, and pregnancy prevention. However, this situation does not mean she engaged in sexual activity. She had other considerations such as her emotional readiness around the physical pain of first intercourse and wanting the right person with which to have her first sexual experience. Drawing on these discourses in her talk has enabled Anggi to resist being positioned as a hormone-driven sexual young person who inevitably engaged in sex once she started dating. 
Similar to Anggi's second reason, Urip's (24, salesperson, male, heterosexual) narrative also contested the constitution of youth as hormone-driven sexual subjects by drawing on the romantic discourse of 'the right chemistry.' Urip has dated a number of girls since high school, and he had sexual intercourse with them. Considering the social importance of virginity especially for Indonesian girls, I asked Urip how he initiated sex with his girlfriends. Urip replied: 'Actually there is no special method. At first I just made them feel comfortable around me, then - because of the conducive atmosphere such as nobody being around and the weather is good - it just happened:') ' (email interview). I also asked how he avoided parental/societal surveillance, and Urip explained that he always found safe places to enjoy sex with his girlfriend where no one will know or care, such as in his rented room, in his girlfriend's rented room, or in the car. He even managed to have sex in his bedroom (at his parents' house) when his parents were at home. However, he engaged in sexual intercourse with only four out of seven girlfriends. Considering his experiences and creativity in finding ways to engage in sex, I was curious as to why he did not have sex with all his girlfriends. Do youth not want sex whenever they have the opportunity, especially male youth (Hollway, 1989) like Urip? Or did some of his girlfriends refuse? Urip answered:

Urip: No, it's not because they refused. Mmm... how to explain it... Of course as a guy sometimes I want to have sex with my girlfriend, but I just feel. It doesn't feel right to me if I do it when I do not feel really sure about her.

Researcher: Not sure about her? Do you mean STIs?

Urip: No, I'm not talking about STIs. It's just like I didn't feel the emotional connection. (Instant messenger interview.)

Urip quickly clarified his accommodation of the male sexual drive discourse (Hollway, 1989) by saying 'of course as a guy sometimes I want to have sex with my girlfriend,' however, his narrative showed that it is not the only discourse he drew upon. By also understanding his sexual self through discursive resources that value romance and the 'right chemistry' in sex, Urip took up an alternative subject position from which he did not need to put STI and unplanned pregnancy prevention at centre stage. Risk avoidance as the main criterion for sexual decisions offered by the discourse of sexual health competed with other criteria such as emotional connectedness. In this way, participants' sexual practice is constituted as something more than a hormone-driven act loaded with risks that must be prevented through contraception, but it is also about relationships, feelings, and chemistry. Urip's way of giving meaning to sexual relationships through discourses of love and romance resonates with previous findings (e.g. Allen, 2003; Allen, 2007) which have identified how discourses of romance have gained more currency in the constitution of young men's sexual subjectivities.

The dominant discourse of sexual health has offered subject positions where Indonesian youth are conceptualised as hormone-driven sexual subjects who always want sex. However, some Indonesian youth in this study have taken up alternative subject positions which contest those conceptualisations of youth's sexual subjectivities. Their narratives demonstrate that not all Indonesian youth are simply driven to engage in sexual activities although they have the opportunity, they do not consider virginity important, and they have the knowledge and skill to initiate sex with their partner. Quite the opposite, they take into account many considerations (beyond STIs and unplanned pregnancy) in order to take care of themselves, such as the avoidance of physical pain, emotional readiness, the right chemistry; or they just do not want sex in each and every dating relationship.

\section{Resisting the positioning of youth as uninformed and vulnerable}

The discourse of sexual health in the existing literature has positioned Indonesian youth as uninformed about sexual health, not making any effort to find sexual health information, and thus exposing themselves to various health risks in their sexual relationships (e.g. Diarsvitri \& Dwisetyani, 2011; Pohan et al., 2011; Widyastari et al., 2015). Educators need to provide sexual health education for 
them, especially about the dangerous risks of sexual activity and the ways to avoid those risks, such as using condoms consistently. However, some participants have resisted these positionings and give alternative meanings to their sexual practices.

Hardly exposed to any kind of formal sexuality education, many participants in this study are actively, creatively, and subversively learning about sexuality themselves. Like youth in other international contexts (e.g. Allen, 2001; Edwards, 2015), these young Indonesian participants have developed their own sexual knowledge by utilising various learning opportunities available to them. Urip (24, salesperson, male, heterosexual), for example, read books about human reproductive anatomy (he could not remember where he got them from) soon after watching his first pornography at age seven. Lusi (22, medical student, female, heterosexual) unintentionally watched a documentary on television about virginity and cultural values. Indra (19, college student, male, heterosexual) knew about condoms from late night television advertisements. Anto (24, NGO activist, male, gay) googled pictures of penises every day after school and found the word 'gay' for the first time, which later provided him with a sense of identity. Putri (22, college student, lesbian) found where the clitoris is when using a wash hose in the toilet, long before knowing the word 'clitoris' itself. Heni (24, postgraduate student, female, asexual) watched her dogs copulate. Jenardi (23, freelance, male, gay) initiated conversations about STIs with an older gay couple he considered his mentors. These youth do not see themselves as ignorant sexual subjects who passively wait for adults to provide them with sexual knowledge. Instead, they actively seek out, and give meaning to, sexuality using various resources available to them.

It can be argued that these kinds of self-learning are very limited and very likely to be 'inaccurate.' The sexual knowledge youth develop could be medically 'incorrect' since the sources available to them are 'unreliable' such as pornography, their own experience, friends, or television. The knowledge these youth develop might not necessarily be the same as the medical knowledge advocated by sexuality educators. However, I argue that it is not less important and not less relevant to their situations, particularly in order to cultivate their own ways of taking care of themselves. As I will demonstrate below, their narratives show alternative ways to understand sex and its risks beyond the universalisedmedicalised-standardised-official knowledge of sexual health. For instance, while sexual health educators often promote condoms as the most reliable prevention against unplanned pregnancy and STIs, some participants found other ways to avoid those health risks and to take care of their well-being. I do not claim that these ways are better or as 'reliable' as modern medical knowledge. My aim here is to disprove the view that participants are always completely unknowledgeable and careless when there is no adult providing them with official sexual health information - which is the view (re)produced through the dominant discourse of sexual health.

Regarding unplanned pregnancy, the participants show more concerns and knowledge about avoiding it compared to avoiding STIs. This is similar to previous studies (Flood, 2003), in which youth view avoiding pregnancy as more important than avoiding STIs. Juwanto (18, high school student, male, heterosexual), for example, lived on the street for three years and engaged in 'various kinds of sin almost every day, such as: smoking, drinking, drugs, watching pornography, and masturbation. But [he] didn't have sex with girls like [his] friends did, because [he] was afraid the girl got pregnant' (autobiographical writing). Juwanto simply maintained abstinence to avoid unplanned pregnancy, because he knew that a man who impregnated a woman was traditionally (Smith-Hefner, 2005) made, by the woman's family, to 'marry and set up a family' with her (autobiographical writing). Daniel (17, high school student, male, heterosexual) was unable to maintain abstinence like Juwanto, but before he had sex he made sure pregnancy would not occur: 'At my first time I was confused and afraid she will get pregnant. I asked her and she said she's on [the] pill so she won't get pregnant' (autobiographical writing). Another method used by some participants to prevent pregnancy is coitus interruptus, which was practised by Yuyun (16, high school student, female, heterosexual), Urip (24, salesperson, male, heterosexual), and Lusi (22, medical student, female, heterosexual). Also, the calendar method was practised by Urip (24, salesperson, male, heterosexual) and Lusi (22, medical student, female, heterosexual). While most of these youth barely had access to official, 
medical sexual health knowledge of condom as contraceptives, drawing on these alternative discourses has enabled them to resist being positioned as ignorant, uninformed, and unconcerned about the risk of unplanned pregnancy.

Regarding STI prevention, some participants in this study also do not rely on condoms as the main method in practising safer sex but other methods instead. Indra (19, college student, male, heterosexual), for instance, replied with certainty when I asked about STIs and his sexual relationships: 'Oh she's clean' (email interview) - which means his girlfriend had never engaged in sex before. Indra did not know about various types of STIs and ways to prevent them, but he knew he was safe by relying on classic categorisation of 'clean' and 'unclean' women (Waldby, Kippax, \& Crawford, 1993). Another example is Hardi (22, office worker, male) who enjoyed sex with multiple partners within his gay community. When I asked about STIs, he said: 'I never used a condom, but we've never inserted penis to anus anyway. We just kissed, hugged, oral, held each other's penis, till the sperm came out. That's all.' (email interview). Hardi has never used condoms, but he knows that the risks of STI infection are much lower where there is no penetration into the body. Within the limited information available to them, these youth show that their understanding of sexual health is not absolute zero. They are relatively informed and paying attention to STI prevention, although their knowledges are not structured around the notion of condoms as prevention against STIs.

Not relying on condom-use to avoid STIs does not mean their knowledges are less valuable, particularly considering the contexts of their sexual experiences. Their alternative knowledges might have provided them with more contextual and relevant practices of taking care of their sexual selves. Put another way, the universalised-medical-official sexual health knowledge of condoms as prevention against STIs and unplanned pregnancy is not always the best in all situations (Bolander, 2015). Rather, it narrowly confines the notion of safer sex into very limited, mechanistic practice. It assumes that sex is only vaginal/anal in heterosexual relationships, and always anal in gay men relationships. As Hardi's (22, office worker, male) narrative above has illustrated, sex among young Indonesian gay youth is not necessarily anal, and thus, condom-use is not the most relevant prevention against STIs. This dominant constitution of sex as a penetrative act has been criticised by previous researchers using the concept of the coital imperative (McPhillips, Braun, \& Gavey, 2001). These researchers called for alternative constitutions of sex beyond coitus, which could also offer more possibilities for practising sex safely in terms of STIs and unplanned pregnancies. Although these acts of sex without penetration are still often unthinkable (McPhillips et al., 2001), what these alternatives look like has been articulated by Hardi: 'We just kissed, hugged, oral, held each other's penis, till the sperm came out. That's all.'

Likewise, the notion of (male) condoms as the ultimate risk-prevention measure is not relevant in the context of lesbian sexual relationships, which do not involve a penis and thus there is no risk of getting pregnant. This is what Bianda (24, office worker, female, bisexual) utilised to enjoy sex without fear of unplanned pregnancy. Identifying herself as bisexual, Bianda chose to engage in sex only with girls because 'ML (making love) with girls cannot cause pregnancy, but with boys there is a possibility to get pregnant, that's why I never tried it (with boys)' (email interview). Bianda also said she has never thought about STIs:

Researcher: Have you ever thought about STIs when having sex with your girlfriend?

Bianda: Nope.

Researcher: Weren't you afraid you could be infected with STIs? Are you sure your partner's free from STIs?

Bianda: Well, I think as long as it's girl with girl, no STls can be passed. Besides, I did it with certain girls whom I think are free from those things. (Instant messenger interview.)

Bianda's convictions are not entirely safe, in that STIs can be passed through sexual activity between women, and her perception of an STI-free local community could be misleadingly dangerous (Flood, 2003). However, she is correct to the extent that STI infections are considerably rarer when no penis is involved (Centers for Disease Control and Prevention, 2010). Bianda's narrative 
shows an alternative way to resist the positioning of youth as completely ignorant or uncaring about unplanned pregnancy and STIs. Instead of focusing on condom-use as offered by the discourse of sexual health, she engaged in another practice which might not be less effective, that is, by limiting her sexual relationships only to women.

Another evidence of contestation toward the dominant meaning of 'safer sex means condom-use' can be seen in participants' narratives who utilised communication technology to engage in and explore sexuality. Computers, smartphones, and high-speed Internet access are widely available among urban Indonesian youth and most of them are familiar with English sources; however, the government has actively censored sexually explicit materials since the passing of anti-pornography bill in 2008. In their online sexually-related activities, some participants show that they have paid attention to their safety and well-being beyond just avoiding STIs and unplanned pregnancy. Jenardi (23, freelance, male, gay), for instance, decided to leave the gay communities in his hometown as he felt tired with 'too many jealousy, drama, and terror' (email interview), including threats of violence from his boyfriend's exes. He realised that his relationships caused danger, not just in terms of STIs and emotional well-being, but also to his physical safety. As he started dating a man from another town, Jenardi found that a sexual relationship mediated by communication technology is much safer in this regard: 'We used mobile phones to see each other and he often felt aroused when he saw me. So he masturbated during our video calls. Doesn't matter, at least this is much safer' (email interview). Correspondingly, Lusi (22, medical student, female, heterosexual) also utilised communication technology to explore and experience sex safely. She had engaged in sex chats with strangers from overseas since she was in intermediate school (age $\pm 13-15$ ). When I asked whether she felt afraid when she first had a sex chat, she said: 'No fear at all on my part. It's because I'm sure that I will not meet that person. Besides, we all use fake names, so no worries at all. Haha.' (instant messenger interview).

Jenardi's and Lusi's narratives are reminiscent of Hillier and Harrison (2007) study on how the Internet can offer a positive and productive space to learn safely about sexuality for young gay and lesbian students. Hillier and Harrison challenged the assumption that adults need to 'police' the use of the Internet by (assumed-to-be) helpless and endangered youth, such as gay and lesbian youth. While the Internet is not sterile from danger, violence, and abusive bullies, Hillier and Harrison identified that gay and lesbian youth have also utilised the Internet to build friendships, develop intimate relationships, and explore sexuality safely. Jenardi, Lusi, and the youth in Hillier and Harrison (2007) present another possibility for resisting the positioning of youth as vulnerable and in urgent need of being saved by adult sexuality educators. While acknowledging there are potential dangers in exploring sexuality, their narratives showed that they have navigated resourcefully in order to learn, experience, and redefine what safer sex might mean.

This section has discussed how participants in this study have resisted the positioning of Indonesian youth as uninformed and vulnerable unless they are provided with official sexual health knowledge by adults. These participants demonstrate that they are knowledgeable and actively take care of themselves by drawing on the alternative discourses available to them. The meanings they give to sexual practice and risk avoidance are not exactly the same as those promoted by sexual health educators. Safer sex does not always mean condom-use, and risks are not always associated with STIs and unplanned pregnancy. I argue, however, that these alternative knowledges and practices are more relevant, contextual, and in some cases, more effective in managing the risks of youth sexual practice. More importantly, this section demonstrates that not all Indonesian youth are (sexually) ignorant and vulnerable. Rather, within the limitations of their situations they have taken care of their own health, safety, and well-being.

\section{Conclusion}

The discourse of sexual health which constitutes youth as always wanting sex, uninformed, and thus vulnerable, denies them recognition of agency. The binary positioning of youth as either completely ignorant (before being provided with sexual health knowledge) or completely responsible (after 
being provided with such knowledge) is problematic in that both assume youth are merely following either their uncontrollable sex drive or adults' advice. Launched from a different premise where the subject is understood as an active agent, this article investigated how young Indonesian participants take up, negotiate, and contest the dominant meanings around youth, sex, and sexual health via the mobilisation of the various discourses to which they have access. This article has presented a range of subject positions occupied by young Indonesian participants, especially those resistant to the dominant discourse of sexual health. Their narratives have demonstrated that there are alternative possibilities for giving meaning to notions of youth, sex, and sexual health which are no less important and relevant to their situations.

One of the limitations of this study is that the findings might not always be completely relevant in other (Indonesian) contexts. Since the data is contextual, situational, and even momentary, readers are invited to reflexively consider the transferability of this study, particularly the possibility to contest the dominant discourses surrounding youth sexuality in their own contexts.

The findings of this study reveal some areas deserving further investigation of their own. As indicated by Jenardi and Lusi who utilised information technology to explore sexuality, future research might examine further how information technology plays a role in Indonesian youth's understanding of themselves as sexual beings and how it shapes their offline sexual lives, including sexual health. Moreover, the advancement and affordability of transportation technologies have made some contemporary Indonesian youth have more geographical mobility including travelling overseas, like Anggi, and enabling them to access different sexual discursive landscapes. Future studies are needed to investigate how Indonesian young people have moved around, explored, and negotiated different geographical contexts and discursive configurations in their becoming sexual subjects.

It is important to note that the implication of this analysis (below) does not intend to undermine the valuable efforts sexual health researchers and educators have made to promote sexual health to Indonesian youth - an endeavour that I committedly support. Instead, this analysis aims to highlight the possibilities and the limitations afforded by the ways of seeing and being sexual subject that are offered by the discourse of sexual health. As in all other ways-of-seeing and ways-of-being, they are always both enabling and constraining, and in need of being continuously contested.

To accommodate the diversity of Indonesian youth's sexual subjectivities, learning about sexual health might not be able to focus solely on filling youth's mind with the 'right' sexual knowledge, or replacing one version of sexual knowledge with another. Instead, learning sexuality might need to be a series of meaning-making activities in which different sexual knowledges are acknowledged and scrutinised. Instead of assuming that all youth are inevitably driven into sexual activities when they start dating, sexual health education may find additional value in acknowledging that, for some youth, sexual relationships are just one part of (or perhaps play no part in) their dating experience. Educational messages may also recognise that sex is not always heterosexual and coital, so that the risks of unplanned pregnancy might not be the only consideration for youth in deciding whether to engage/not engage in sex. Rather, there are other kinds of sexual practices that Indonesian youth engage in, such as same-sex, non-coital, or computer-mediated sexual activities. There are also other health considerations to take into account, such as their physical safety and emotional readiness. Youth can then be encouraged to reflect on and discuss their personal learning moments, as well as information they receive from formal sources, in order to develop their own sexual knowledges, values, and make decisions. Through a recognition and examination of various sexual knowledges (including their limitations), sexual health education might engage more effectively with the complexities of Indonesian youth's sexual subjectivities, and encourage more diverse ways of being a sexual subject.

\section{Acknowledgments}

This work was made possible by the Indonesian Directorate of General of Higher Education (DIKTI) under Beasiswa Luar Negeri (BLN) scholarship scheme. 


\section{Disclosure statement}

No potential conflict of interest was reported by the author.

\section{Funding}

This work was supported by the Direktorat Jenderal Pendidikan Tinggi, Indonesia.

\section{Notes on contributor}

Teguh Wijaya Mulya is a lecturer in psychology at the University of Surabaya, Indonesia. He is a graduate of the University of Surabaya, Monash University, and the University of Auckland. He specialises in research in the areas of sexuality, gender, and religion. His work is inspired by the work of Michel Foucault and post-structuralist feminism.

\section{ORCID}

Teguh Wijaya Mulya iD http://orcid.org/0000-0002-8899-1157

\section{References}

Allen, L. (2001). Closing sex education's knowledge/practice gap: The reconceptualisation of young people's sexual knowledge. Sex Education: Sexuality, Society and Learning, 1(2), 109-122.

Allen, L. (2003). Girls want sex, boys want love: Resisting dominant discourses of (hetero) sexuality. Sexualities, 6(2), 215-236.

Allen, L. (2007). Denying the sexual subject: Schools' regulation of student sexuality. British Educational Research Journal, 33(2), 221-234.

Bennett, L. R. (2007). Zina and the enigma of sex education for Indonesian Muslim youth. Sex Education, 7(4), 371-386.

Bolander, E. (2015). The condom works in all situations? Paradoxical messages in mainstream sex education in Sweden. Sex Education, 15(3), 289-302.

Borland, K. (1991). "That's not what I said": Interpretive conflict in oral narrative research. In S. G. Berger \& D. Patai (Eds.), Women's words: The feminist practice of oral history (pp. 63-75). New York: Routledge.

Braun, V. (2013). 'Proper sex without annoying things': Anti-condom discourse and the 'nature' of (hetero) sex. Sexualities, 16(3-4), 361-382.

Braun, V., \& Clarke, V. (2006). Using thematic analysis in psychology. Qualitative Research in Psychology, 3(2), 77-101.

Browne, K., \& Nash, C. J. (Eds.). (2010). Queer methods and methodologies: Intersecting queer theories and social science research. Burlington, VT: Ashgate.

Butler, J. (1990). Gender trouble: Feminism and the subversion of identity. New York: Routledge.

Centers for Disease Control and Prevention. (2010). HIV transmission. Retrieved from http://www.cdc.gov/hiv/ resources/qa/transmission.htm

Chase, S. E. (1996). Personal vulnerability and interpretive authority in narrative research. In R. Josselson (Ed.), Ethics and process in the narrative study of lives (pp. 45-59). Thousand Oaks, CA: Sage.

Diarsvitri, W., \& Dwisetyani, I. (2011). The importance of reproductive health and HIVAIDS education program for young people in Papua and West Papua Provinces, Indonesia. Journal of Epidemiology and Community Health, 65 (Suppl 1), A102.

Diarsvitri, W., Utomo, I. D., Neeman, T., \& Oktavian, A. (2011). Beyond sexual desire and curiosity: Sexuality among senior high school students in Papua. Culture, Health \& Sexuality, 13(9), 1047-1060.

Edwards, N. (2015). Women's reflections on formal sex education and the advantage of gaining informal sexual knowledge through a feminist lens. Sex Education, 16(3), 266-278.

Fields, J. (2008). Risky lessons: Sex education and social inequality. New Brunswick: Rutgers University Press.

Flanders, C. E., Ross, L. E., Dobinson, C., \& Logie, C. H. (2017). Sexual health among young bisexual women: A qualitative, community-based study. Psychology \& Sexuality, 8(1-2), 104-117.

Fletcher, G. (2015). The knowledge gap: Examining the rhetoric and implementation of peer education for HIV prevention in Myanmar. Sex Education, 15(4), 378-391.

Flood, M. (2003). Lust, trust and latex: Why young heterosexual men do not use condoms. Culture, Health and Sexuality, 5(4), 353-369.

Harding, C. (2008). The influence of the 'decadent west': Discourses of the mass media on youth sexuality in Indonesia. Intersections: Gender and Sexuality in Asia and the Pacific, 18. 
Hillier, L., \& Harrison, L. (2007). Building realities less limited than their own: Young people practising same-sex attraction on the internet. Sexualities, 10(1), 82-100.

Hollway, W. (1989). Subjectivity and method in psychology: Gender, meaning and science. London: Sage.

Josselson, R. (2007). The ethical attitude in narrative research: Principles and practicalities. In D. J. Clandinin (Ed.), Handbook of narrative inquiry: Mapping a methodology (pp. 537-565). Thousand Oaks, CA: Sage.

Kippax, S. (2010). Safe sex: It's not as simple as ABC. In P. Aggleton \& R. Parker (Eds.), Routledge handbook of sexuality, health and rights (pp. 184-192). New York: Routledge.

Leerlooijer, J. N., Ruiter, R. A. C., Reinders, J., Darwisyah, W., Kok, G., \& Bartholomew, L. K. (2011). The world starts with me: Using intervention mapping for the systematic adaptation and transfer of school-based sexuality education from Uganda to Indonesia. Translational Behavioral Medicine, 1, 331-340.

McPhillips, K., Braun, V., \& Gavey, N. (2001). Defining (hetero) sex: How imperative is the "coital imperative"? Women's Studies International Forum, 24(2), 229-240.

Munro, J., \& Butt, L. (2012). Compelling evidence: Research methods, HIV/ AIDS,and politics in Papua, Indonesia. The Asia Pacific Journal of Anthropology, 13(4), 334-351.

Pohan, M. N., Hinduan, Z. R., Riyanti, E., Mukaromah, E., Mutiara, T., Tasya, I. A., ... Hospers, H. J. (2011). HIV-AIDS prevention through a life-skills school based program in Bandung, West Java, Indonesia: Evidence of empowerment and partnership in education. Procedia Social and Behavioral Sciences, 15, 526-530.

Simon, S., \& Paxton, S. J. (2004). Sexual risk attitudes and behaviors among young adult Indonesians. Culture, Health \& Sexuality, 6(5), 393-409.

Smith, G., Kippax, S., \& Aggleton, P. (2000). HIV and sexual health education in primary and secondary schools: Findings from selected Asia-Pacific countries. Sydney: National Centre in HIV Social Research, University of New South Wales.

Smith-Hefner, N. J. (2005). The new muslim romance: Changing patterns of courtship and marriage among educated javanese youth. Journal of Southeast Asian Studies, 36(3), 441-459.

Teye-Kwadjo, E., Kagee, A., \& Swart, H. (2017). Determinants of condom use among heterosexual young men and women in southeastern ghana: A mediation analysis. Psychology \& Sexuality, 8(4), 291-305.

Utomo, I. D., \& McDonald, P. (2009). Adolescent reproductive health in Indonesia: Contested values and policy inaction. Studies in Family Planning, 40(2), 133-146.

Waldby, C., Kippax, S., \& Crawford, J. (1993). Cordon sanitaire: 'Clean' and 'unclean' women in the AIDS discourse of young men. In P. Aggleton, P. Davies, \& G. Hart (Eds.), AIDS: Facing the second decade (pp. 29-39). London: Falmer Press.

Weedon, C. (1987). Feminist practice and poststructuralist theory. Oxford: Blackwell.

Widyastari, D. A., Isarabhakdi, P., \& Shaluhiyah, Z. (2015). "Women won't get pregnant with one sexual intercourse": Misconceptions in reproductive health knowledge among Indonesian young men. Journal of Health Research, 29(1), 63-69.

Wijaya Mulya, T. (2017). From divine designation to discursive contestation: The constitution of Indonesian Christian young people's sexual subjectivities. New Zealand: (Doctor of Philosophy), University of Auckland.

Wijaya Mulya, T. (2018). From divine instruction to human invention: The constitution of Indonesian Christian young people's sexual subjectivities through the dominant discourse of sexual morality. Asian Studies Review, 42(1), 53-68.

Willig, C. (2013). Introducing qualitative research in psychology. Berkshire: Open University Press. 


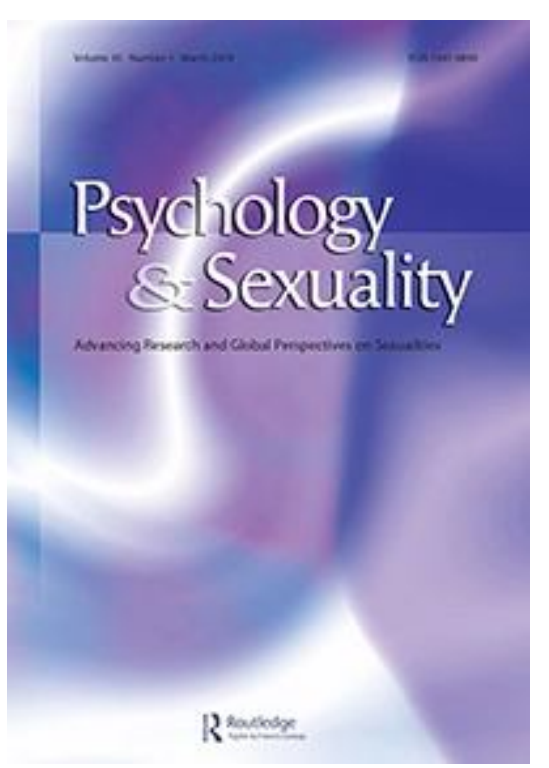


Journal

Psychology \& Sexuality >

\section{Explore}

This journal

\section{Latest articles}

Articles

Article

From vulnerable to responsible youth? Indonesian youth resisting the dominant discourse of sexual health >

Teguh Wijaya Mulya

Published online: 13 Apr 2019

\begin{tabular}{l|l|l}
\hline 0 & 0 & 0 \\
Views & CrossRef citations & Altmetric
\end{tabular}

Article

A mixed-methods measurement study of female adolescent sexuality stress and support >

Katherine K. Bedard-Thomas, John L. McKenna, David W. Pantalone, Gary Fireman \& Amy K. Marks Published online: 10 Apr 2019

\begin{tabular}{l|l|l}
6 & 0 & 0 \\
Views & CrossRef citations & Altmetric
\end{tabular}

LGBQ resilience: a thematic meta-synthesis of qualitative research > Sebastian E. Bartoș \& Darren Langdridge 
Article

A comparative analysis of rural and urban MSM depressive symptomology: the mediating effects of loneliness >

Zachary Giano, Randolph D. Hubach, Kyle Deboy, Hunter Meyers, Joseph M. Currin \& Denna L. Wheeler

Published online: 17 Mar 2019

\begin{tabular}{l|l|l}
49 & 0 & 4 \\
Views & CrossRef citations & Altmetric
\end{tabular}

\section{Article}

Heteronormativity and women's psychosocial functioning in heterosexual and same-sex couples >

Janice M. Habarth, Robert E. Wickham, Katrina M. Holmes, Michaela Sandoval \& Kimberly F. Balsam Published online: 05 Mar 2019

\begin{tabular}{l|l|l}
\hline 60 & 0 & 0 \\
Views & CrossRef citations & Altmetric
\end{tabular}

Article

Affirmation, compartmentalization, and isolation: narratives of identity sentiment among kinky people >

Sam D. Hughes \& Phillip L. Hammack

Published online: 22 Feb 2019

\begin{tabular}{l|l|l}
\hline 59 & 0 & 7 \\
Views & CrossRef citations & Altmetric
\end{tabular}

Article

Exploring the relationship between gay men's self- and metastereotype endorsement with well-being and self-worth >

Jordan D. X. Hinton, Joel R. Anderson \& Yasin Koc 
Journal

\section{Psychology \& Sexuality >}

\section{This journal}

\section{Journal information}

Print ISSN: 1941-9899 Online ISSN: 1941-9902

4 issues per year. 2 issues will be print.

Psychology \& Sexuality is currently indexed in Scopus.

Taylor \& Francis make every effort to ensure the accuracy of all the information (the "Content") contained in our publications. However, Taylor \& Francis, our agents, and our licensors make no representations or warranties whatsoever as to the accuracy, completeness, or suitability for any purpose of the Content. Any opinions and views expressed in this publication are the opinions and views of the authors, and are not the views of or endorsed by Taylor \& Francis. The accuracy of the Content should not be relied upon and should be independently verified with primary sources of information. Taylor \& Francis shall not be liable for any losses, actions, claims, proceedings, demands, costs, expenses, damages, and other liabilities whatsoever or howsoever caused arising directly or indirectly in connection with, in relation to, or arising out of the use of the Content. Terms \& Conditions of access and use can be found at http://www.tandfonline.com/page/terms-and-conditions .

Sample Our

Humanities journals

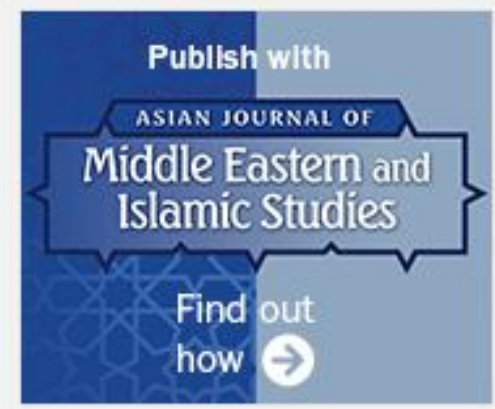


Journal

\section{Psychology \& Sexuality >}

\section{This journal}

\section{Editorial board}

\section{Editors}

Daragh McDermott - Anglia Ruskin University, UK

Todd Morrison - University of Saskatchewan, Canada

Associate Editors

Karen Blair - St Francis Xavier University, Canada

Nikki Hayfield - University of West England, UK

Adam Jowett - Coventry University, UK

Jessica McCutcheon - University of Saskatchewan, Canada

Poul Rohleder - University of Essex, UK

\section{Editorial Board}

Barry Adam - Windsor University, Canada

Meg-John Barker - The Open University, UK

CJ Bishop - University of Saskatchewan, Canada

Angelo Brandelli-Costa - Pontifica Universidade Catolica do Rio Grande do Sul, Brazil Joseph Brennan - University of Sydney, Australia

Ashley Brooks - Anglia Ruskin University, UK

Jill Chonody - Indiana University, USA

Susan Cochran- University of California, Los Angeles USA

Shelly Craig - University of Toronto, Canada

Richard de Visser - University of Sussex, UK

Lisa Downing - University of Birmingham, UK

Daniel Farr - Kennesaw State University, USA

Corey Flanders - Mt Holyoke University, USA

Paul Flowers - Glasgow Caledonian University, UK

Peter Hegarty - University of Surrey, UK

Rhea Ashley Hoskin - Queens University, Canada

Peggy Kleinplatz - University of Ottawa, Canada

Darren Langdridge - The Open University, UK

Rosemary Lobban - University of Greenwich, UK 
Russell Luyt - University of Greenwich, UK

Sam Martin - Anglia Ruskin University, UK

Lorraine McDonagh - University College London, UK

Martin Milton - Regents University, UK

Melanie Morrison - University of Saskatchewan, Canada

David A. Moskowitz - Northwestern University, USA

Elly-Jean Nielsen - University of Saskatchewan, Canada

Sonny Nordmarken - University of Massachusetts Amherst, USA

Elizabeth Peel - Loughborough University, UK

Paula Reavey - London South Bank University, UK

Damien W. Riggs - Flinders University, Australia

Kathleen Ritter - California State University, Bakersfield, USA

Ian Rivers - University of Strathclyde, UK

Esther D. Rothblum - San Diego State University, USA

BJ Rye - University of Waterloo, Canada

Theo Sandfort - Columbia University, USA

Ayden Schiem - University of Western Ontario, Canada

Dan Shepperd - Aston University, UK

Eric Swank - Arizona State University, USA

Fiona Tasker - Birkbeck College, University of London, UK

Evangelos Tziallas - Concordia University, Canada

Jane Ussher - University of Western Sydney, Australia

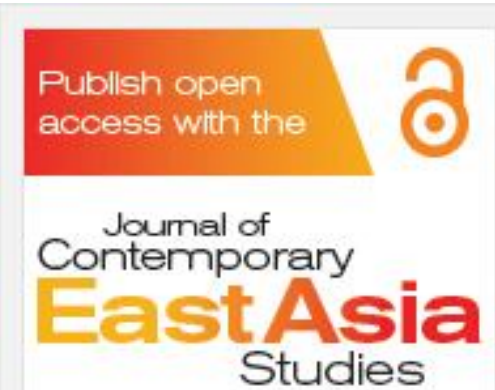




\section{SJR}

Scimago Journal \& Country Rank Enter Journal Title, ISSN or Publisher Name

Home Journal Rankings

\section{Psychology and Sexuality}

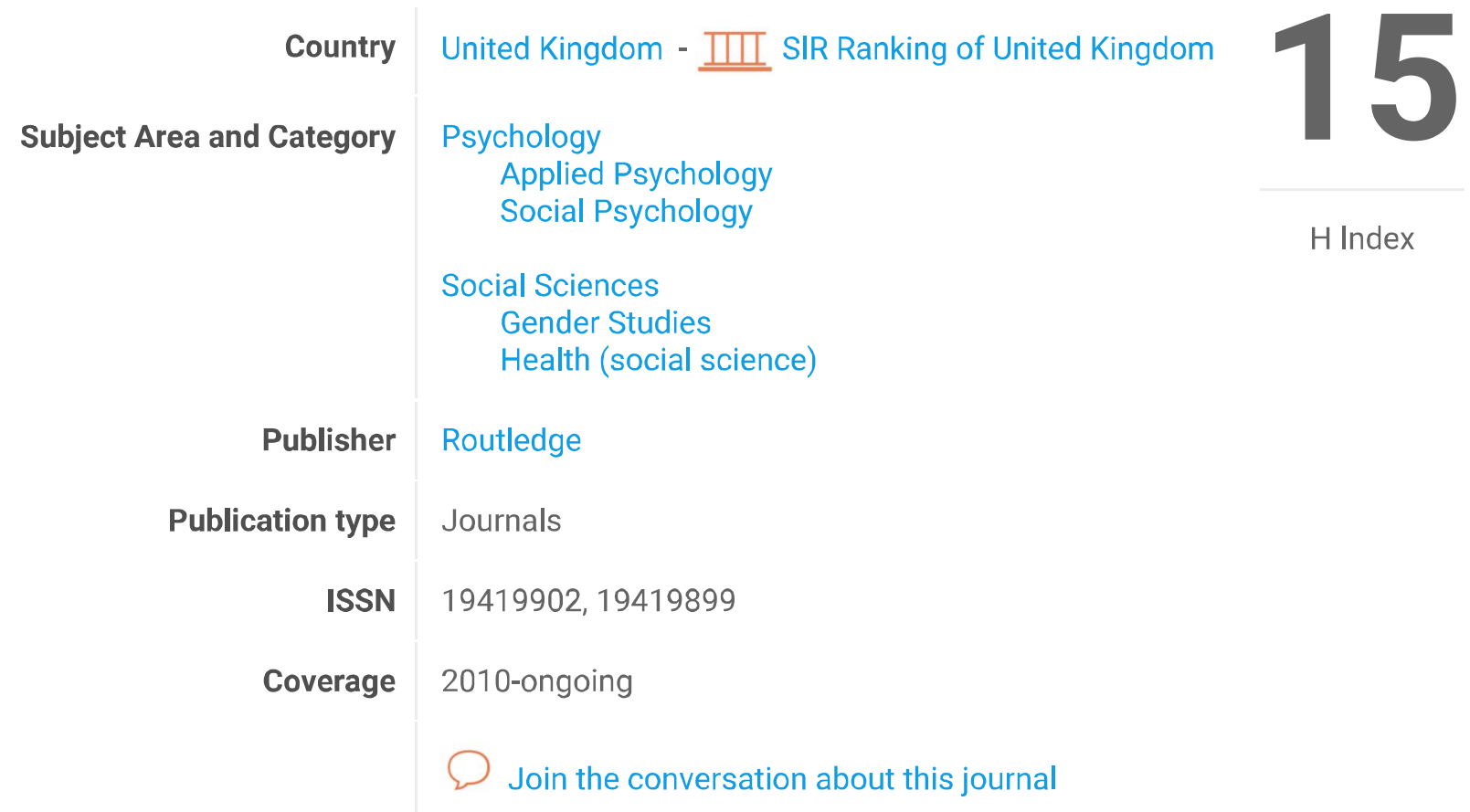

Quartiles
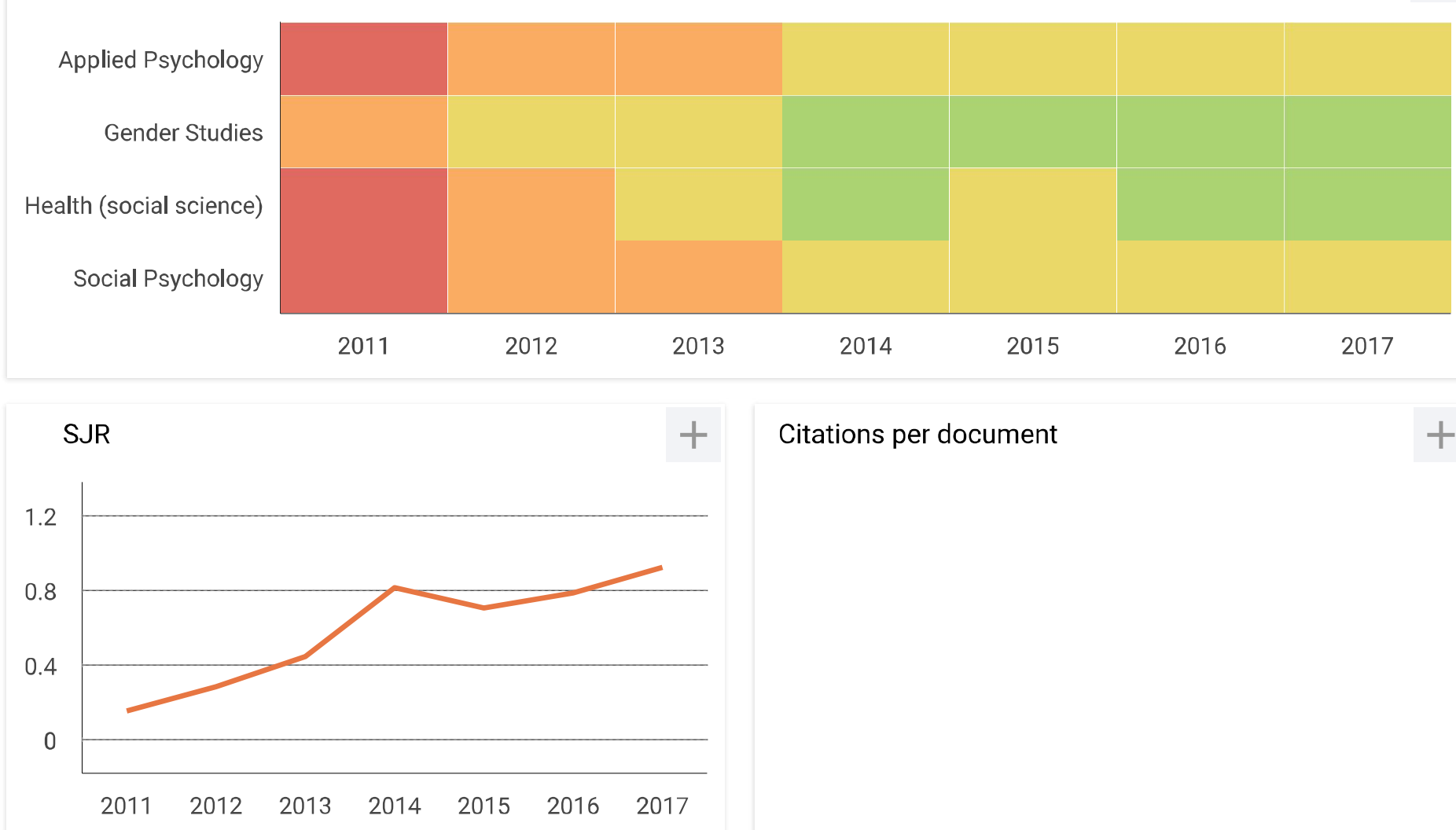

Citations per document

Total Cites Self-Cites 


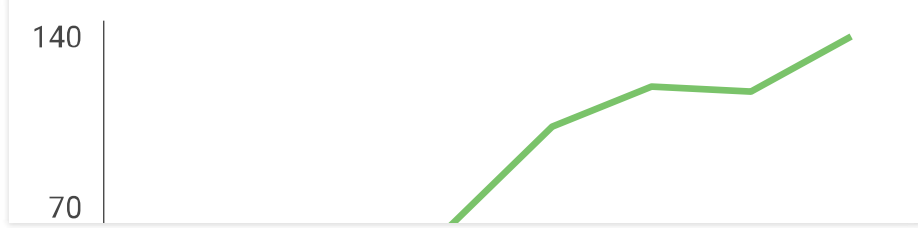

External Cites per Doc

Cites per Doc

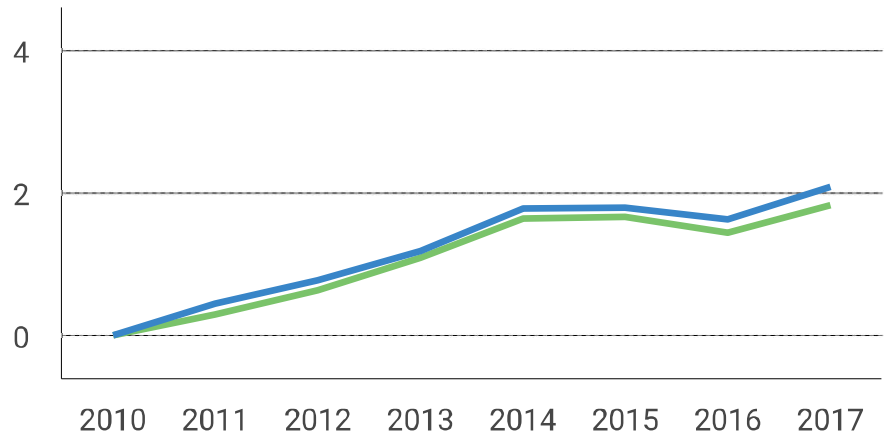

Citable documents Non-citable documents +

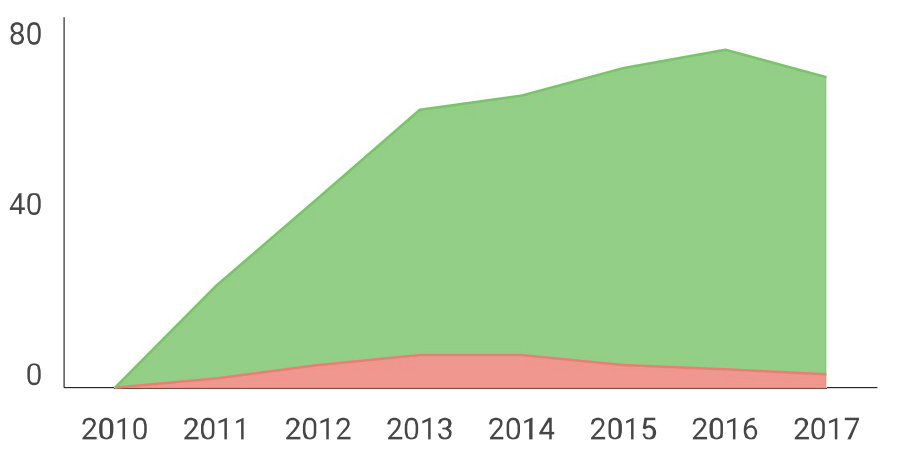

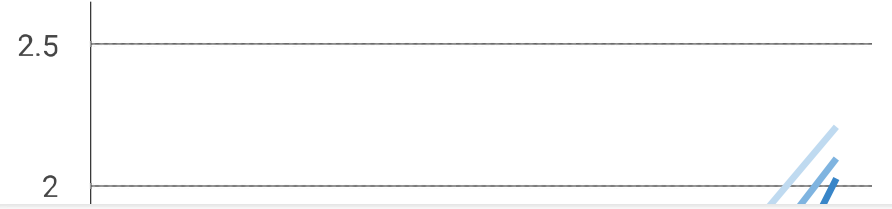

\section{$\%$ International Collaboration}

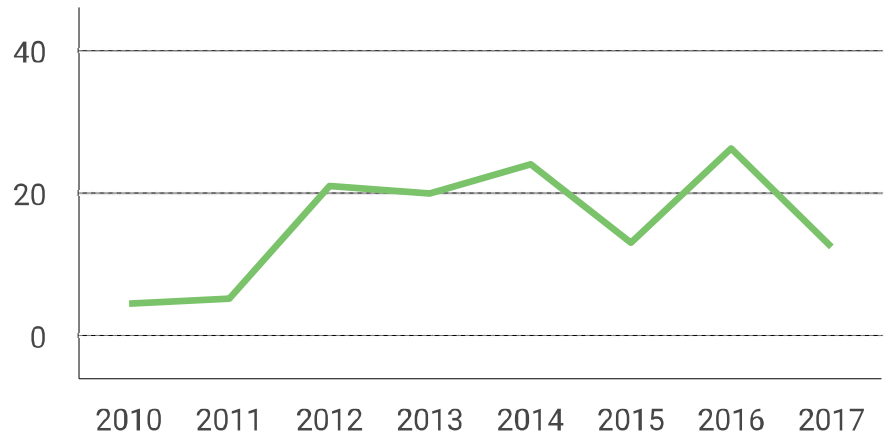

\section{Cited documents Uncited documents}

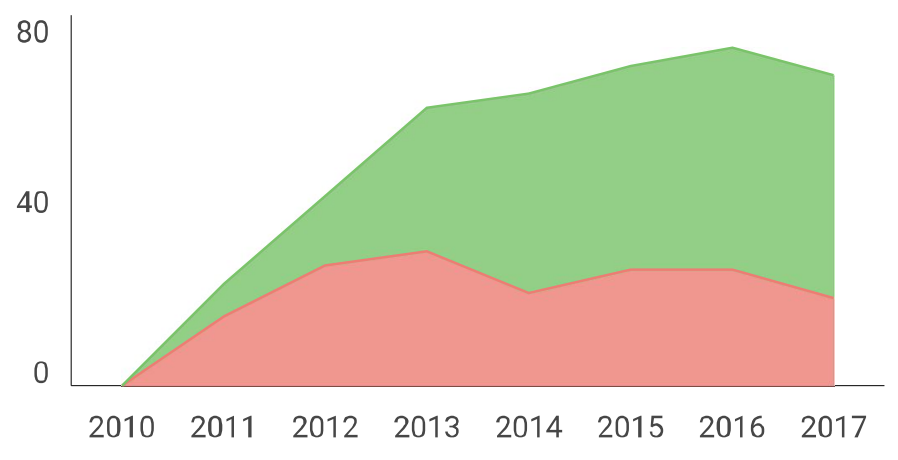

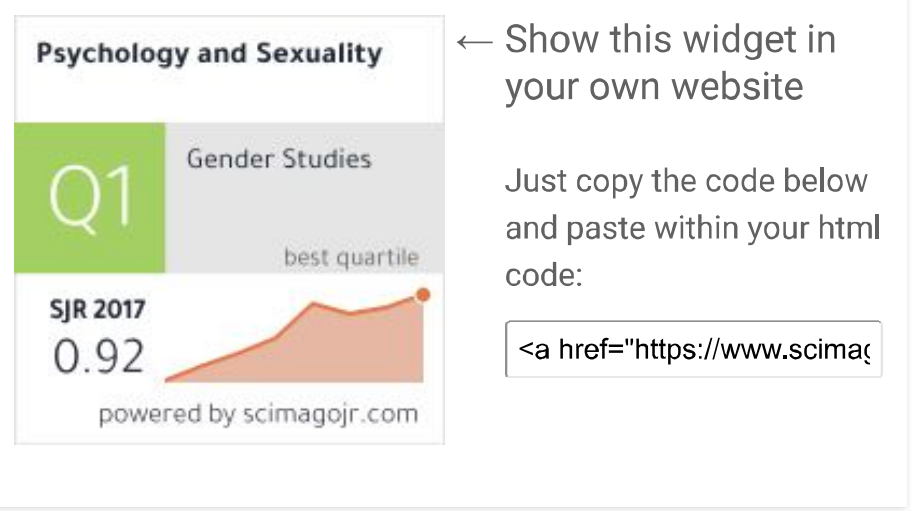

\section{Leave a comment}

\section{Name}

\section{Email}

(will not be published) 